\title{
“As Many as Possible for as Long as Possible”-A Case Study of a Soccer Team That Fosters Multiple Outcomes
}

\author{
Martin K. Erikstad \\ University of Agder and Nord University
}

\author{
Bjørn Tore Johansen, Marius Johnsen, and Tommy Haugen \\ University of Agder
}

\author{
Jean Côté \\ Queen's University
}

\begin{abstract}
The personal assets framework suggests that dynamic elements of (a) personal engagement in activities, (b) quality social dynamics, and (c) appropriate settings will influence an athlete's long-term outcomes of performance, personal development, and continued participation in sport. The aim of the present study was to conduct a case study of a Norwegian age-restricted team that was successful in promoting participation, performance, and positive development for individual participants and to investigate how the dynamic elements of activities, social dynamics, and settings have led to these long-term outcomes. The results indicated that the case is a best-practice example of successful attainment of personal development and long-term participation and performance through appropriate structure and application of the dynamic elements within the personal assets framework, including enjoyable peer-led play activities and quality practice, quality relationships with teammates and coaches, and access to facilities.
\end{abstract}

Keywords: personal assets, positive youth development, sport participation, talent development, youth soccer, youth sport

Participation in sport is highly popular worldwide (Eime et al., 2015; Hulteen et al., 2017). For example, more than 1.9 million people in Norway - over $35 \%$ of the population-are registered in a sport club, with children and youth sport experiencing the highest participation rates (Norwegian Olympic and Paralympic Committee and Confederation of Sports, 2017). Sport participation is generally considered a beneficial arena for obtaining various adaptive outcomes, such as good physical and mental health (see Eime et al., 2013 for a review), positive youth development (Holt, 2016), and high levels of performance (Haugaasen \& Jordet, 2012; Rees et al., 2016).

It has been proposed that the adaptive outcomes of sport participation can be grouped into the three P's of performance (the development of sport expertise), participation (engagement in sport or physical activity throughout life), and personal development (healthy psychological, social, and emotional development; Côté et al., 2014; Côté et al., 2016). However, sport participation alone does not seem to be sufficient to explain the attainment of these

(C) 2021 The Authors. Published by Human Kinetics, Inc. This is an Open Access article distributed under the terms of the Creative Commons Attribution-NonCommercial-NoDerivatives 4.0 International License, CC BY-NC-ND 4.0, which permits the copy and redistribution in any medium or format, provided it is not used for commercial purposes, no modifications are made, appropriate credit is given, and a link to the license is provided. See http://creativecommons.org/licenses/ by-nc-nd/4.0. This license does not cover any third-party material that may appear with permission in the article. For commercial use, permission should be requested from Human Kinetics, Inc., through the Copyright Clearance Center (http://www. copyright.com).

Erikstad, Johansen, Johnsen, and Haugen are with the University of Agder, Kristiansand, Norway. Erikstad is also with Nord University, Bodø, Norway. Côté is with Queen's University, Kingston, ON, Canada. Erikstad (martin.erikstad@uia. no) is the corresponding author. long-term adaptive outcomes, as sport participation also can lead to maladaptive results, such as burnout, stress, and dropout (Crane \& Temple, 2015; Fraser-Thomas et al., 2008). Indeed, participation rates in sport have been found to decline through adolescence (Zimmermann-Sloutskis et al., 2010), for instance, as competition focus becomes increasingly important for sport organizations (Skille, 2011). Thus, long-term goals of achieving higher levels of skills in sport often come at the cost of immediate gratification and enjoyment (Côté \& Abernethy, 2012).

Côté and colleagues (Côté et al., 2014; Côté et al., in press) proposed the personal assets framework (PAF) to describe the interacting elements that, over time, influence performance, personal development, and continued participation in sport. Particularly, the PAF asserts that youths' sport experiences are shaped by three dynamic elements: (a) personal engagement in activities, (b) quality social dynamics, and (c) appropriate physical and competitive setting. In a limited time frame (e.g., one season), the characteristics and interactions of these dynamic elements will influence a person's competence, confidence, connections, and character (i.e., four C's; Côté et al., 2010; Little, 1993). The PAF suggests that an enhancement of the four C's is associated with positive sport experiences that can lead to long-term (e.g., over multiple seasons) performance, participation, and personal development (i.e., three P's) outcomes (Côté et al., 2014). The PAF thereby presents a multisystem perspective of youth sport, supported by research highlighting the importance of activities, relationships, and settings on three P's outcomes (e.g., Henriksen et al., 2010a; Turnnidge et al., 2014; Vella et al., 2011).

Sport research has typically focused on the importance of one isolated dynamic element (e.g., activities) on one outcome (e.g., performance). For instance, the activities element of sport engagement has often been examined in terms of the types and amounts of play and practice activities needed to develop an expert level of 
performance (see Coutinho et al., 2016 for a review). Côté et al. (2007) developed the Developmental Model of Sport Participation (DMSP) to describe two main developmental pathways that lead to various developmental outcomes: (a) the early specialization pathway, characterized by large amounts of deliberate forms of practice from an early age, and (b) the early sampling pathway, characterized by large amounts of play activities and participation in different sports from an early age. Although researchers still debate the importance of childhood engagement in play and practice activities throughout childhood for the development of expertise (Ford et al., 2015; Ford \& Williams, 2017), the current state of knowledge generally supports the notion that peer-led play activities throughout childhood are beneficial before specializing in adolescence (Baker \& Young, 2014; Coutinho et al., 2016; Memmert et al., 2010). Playing different sports in childhood may also provide a breadth of experiences (e.g., social, physical, and emotional) that can be beneficial for continued involvement in sport (Fredricks \& Eccles, 2006). Early specialization, on the other hand, may lead to negative sport experiences (e.g., burnout or reduced enjoyment) and increased risk of dropout (Fraser-Thomas et al., 2008; Myer et al., 2015). However, DiSanti and Erickson (2020) have recently criticized the sport specialization literature for its lack of holistic consideration for athlete development, advocating researchers to use ecologicalgrounded theories to also emphasize contextual factors and the interplay between various social actors involved. Thus, to be developmentally sound, diversification and deliberate play in childhood need to be integrated within an appropriate physical/competitive setting with quality social dynamics.

Indeed, a vast amount of research shows that long-term outcomes in sport are influenced by various social agents, such as individuals within the family (Côté, 1999), the coach (Arthur et al., 2017), and teammates (Martin et al., 2014). More specifically, the coach has an important role as the leader of the team (Price \& Weiss, 2013), which may influence athletes' performance, participation, and personal development (Côté \& Gilbert, 2009; Vella et al., 2011). Specifically, an increasing body of evidence is highlighting transformational leadership behaviors by coaches as particularly beneficial for promoting athletes' positive outcomes (Arthur et al., 2017; Stenling \& Tafvelin, 2014; Tucker et al., 2010; Turnnidge \& Côté, 2016). Transformational leaders inspire, challenge, and motivate followers to reach their potential through idealized influence, inspirational motivation, intellectual stimulation, and individual consideration (Bass \& Riggio, 2006). Furthermore, youth team sport athletes spend a considerable amount of time with teammates throughout development (Ward et al., 2007), where the interactions and characteristics of the group may affect individuals (Martin et al., 2014). Accordingly, both social and task cohesion have been positively associated with relationships and social dynamics that optimize young athletes' engagement in sport (Bruner et al., 2014).

The third dynamic element of the PAF is an appropriate setting that addresses how the broader physical and competitive environment may shape athletes' personal assets. Research has been consistent in finding that where an athlete is born may influence the development of personal assets and long-term engagement in sport (i.e., birthplace effects; Côté et al., 2006). In a classic study, Curtis and Birch (1987) demonstrated that city size influences the likelihood of becoming a Canadian Olympic or National Hockey League ice hockey player, where large (greater than 500,000 inhabitants) and small (fewer than 1,000 inhabitants) regions produced fewer elite athletes than the expected proportion. More recently, studies have found that athletes from smaller cities have prolonged engagement in sport and are less likely to drop out of sports when compared with athletes of larger urban center (Imtiaz et al., 2014; Turnnidge et al., 2014) and also score higher on personal development indicators (e.g., commitment to learning and positive identity; Fraser-Thomas et al., 2010). It is suggested that explanations for such findings may be that smaller communities can offer better opportunities for peer-led sport activities and supportive social relationships, as well as promote higher perceptions of competence (Côté et al., 2014; Zell \& Alicke, 2010).

By investigating the larger systems that interact to contribute to athlete development, studies have indicated that factors at both the micro- (i.e., settings of athletes' daily interactions) and macro-level (i.e., more distant forces such as the sport federation) may influence an athlete's sport experiences, career development, and transitions (Henriksen et al., 2014; Henriksen et al., 2010b; Henriksen et al., 2011; Stambulova \& Alfermann, 2009). For instance, Henriksen and colleagues conducted three case studies on sport clubs that regularly produced international-level athletes and found proximity to elite athletes, a "whole-person-approach," cohesiveness, and focus on long-term development to be among the characteristics of the environments (Henriksen et al., 2010a; Henriksen et al., 2010b; Henriksen et al., 2011). Furthermore, Balish and Côté (2014) highlighted that some communities are more successful in developing elite athletes than others. By investigating a Canadian community that was successful in developing elite athletes, Balish and Côté identified three distinct themes that characterized the community: (a) developmental experiences (e.g., participation in organized and unorganized sport activities with stable teammates throughout development), (b) community influences (e.g., accessible facilities and stable relationships), and (c) socio-cultural influences (e.g., collective identity). Furthermore, in a qualitative study of a community youth sport program that successfully promoted positive youth development, coaches reported opportunities to play the sport, develop quality relationships with coaches and peers, and participate in competitive games with equal distribution of playing time across team members (Vierimaa et al., 2017). Bearing in mind that findings from such case studies lack generalizability to wider populations, the aforementioned research has provided valuable insight into the processes and characteristics of various successful cases. However, the success of these cases is mainly delimited to either performance, participation, or personal development, highlighting the need for studies that address how more than one of these outcomes may be obtained simultaneously.

In summary, sport has the potential to influence the long-term outcomes of performance, participation, and personal development (Côté et al., 2014). However, it could be argued that these outcomes may be difficult to obtain simultaneously without sacrificing one outcome over another. For instance, the development of expert performance in the long term may come at the cost of athletes' positive sport experiences or personal development (Fraser-Thomas et al., 2008). Studies have investigated isolated cases that have been successful in the development of long-term participation or performance (Balish \& Côté, 2014; Henriksen et al., 2014); however, a dearth of research remains regarding cases that have been successful in developing multiple outcomes simultaneously (e.g., participation, performance, and positive development). Accordingly, the aim of the present study was to conduct a case study of a team that had individual athletes who had achieved a high level of performance or long-term recreational participation and successfully navigated life challenges (e.g., personal development), to understand the characteristics of the physical settings, social dynamics, and sport activities that may have led to these outcomes. 


\section{Method}

\section{Research Design and Paradigm}

The present study was positioned within a phenomenological tradition (see Allen-Collinson, 2009), and an interpretivist understanding was applied to discover reality through informants' views, background, and experiences (Schwartz-Shea \& Yanow, 2013; Thanh \& Thanh, 2015). This approach was underpinned by an epistemological constructivist (i.e., knowledge is subjective and socially constructed) and a relativistic perspective (i.e., the reality is subjective and minddependent). Thus, a case study design was applied in the present study. Such a method allows an in-depth examination of a phenomenon through multiple sources of evidence and was considered appropriate to describe the underlying mechanisms that may have contributed to the realization of adaptive sport outcomes in a specific singular successful case. In addition to conducting interviews, training diaries were examined. This allowed the investigators to supplement the informants' subjective perceptions with more objective evidence, as recommended by Stambulova (1994).

\section{Case Selection and Description}

An age-restricted team from the Norwegian soccer club Bryne FC was selected for the present study. Bryne FC has approximately 750 registered members and is from the city of Bryne on the west coast of Norway, which has a population of approximately 12,000 people. The male senior team of Bryne has traditionally played competitively at Level 1 or 2 in Norway (the two highest levels of the Norwegian soccer league system) but was relegated to Level 3 in 2016. The team in the present study was established as a grassroots soccer team (with no entrance requirements) for a cohort of boys born in Bryne in 1999. Norwegian soccer is generally characterized by high participation rates among children and youths and has specific regulations to avoid exposing children under 13 years to intense competition, such as disallowing national competitions and arrangements involving resultsbased prizes (see Tuastad, 2019). The team played together as an agerestricted team from the time players were 5-6 years old until approximately reaching age 16 . At this point, the team was restructured due to the Norwegian League system. However, the majority of the group continued playing together at the junior level in Bryne (approximately aged 17-19 years), while others were recruited to senior soccer. The team was selected for the present study due to three main characteristics that aligned with the purpose of the study: (a) several players became professional players (performance), (b) the team experienced low dropout rate (participation), and (c) there were indicators that the players experienced personal development through their contribution to the team and their community.

In terms of performance indicators, 10 of 40 players were selected at the regional level, ${ }^{1}$ indicating they were considered among the most promising players within their region (i.e., Rogaland). Furthermore, five players were selected for the Norwegian U-national team. As of August 2020, six of the players progressed to play senior soccer at a professional level (i.e., obtained a professional contract), including one player in the Norwegian Premier League and two players earning professional contracts in international clubs at Champions League level. In addition to having produced high-performing athletes, the team has also been known for its remarkably low dropout rate. In fact, personal communications with the club revealed that teams in Bryne FC often were dissolved or restructured between the ages of 13 and 16 due to dropout; however, on the present team, 35 of 40 players continued playing soccer until entering adulthood. Finally, some social indicators showed that the athletes on the team experienced personal development, as the players promoted fair play and demonstrated good behavior outside the sport domain. More particularly, publicly available documents in Norway, including articles in Norwegian national newspapers and coach presentations at various seminars, suggest that this specific group of athletes had positive social interactions, promoted fair play, and contributed to their communities outside the sport domain.

\section{Informants}

We first approached the head coach of the Bryne team with an invitation to participate in the study. The coach was the father of two players on the team and had coached the group voluntarily throughout its existence. He started taking formal coaching courses after he retired from competitive soccer due to injuries in his youth and holds a Union of European Football Associations (UEFA) A license (the second-highest coaching license mandated by UEFA, the official governing body of European soccer). Prior to coaching the team, he had coached various other soccer groups, including age-restricted and senior teams. Besides coaching, he worked as a teacher at an upper secondary school and thus holds formal pedagogic competence. After the coach was informed and agreed to partake in the study, four players, four parents, and one club representative (i.e., the person that was responsible for player development in Bryne during this period) were invited to participate in the study. Selection of the athletes, parents, and representatives was done through purposeful sampling (Patton, 2002; Tongco, 2007), where the coach was asked to identify players and parents that could provide insightful information about the Bryne team. Such deliberate choice of informants is considered appropriate when aiming to use the most information-rich sources about a phenomenon (Etikan et al., 2016). To ensure data were collected from both recreational and professional players, the coach was asked to identify two players who had progressed to a professional level and two players who had been part of the team for recreational purposes (e.g., social and/or enjoyment motives). Similarly, the coach was asked to identify four parents (two elite and two recreational) who could provide adequate information about their child's involvement in the team. The final sample thereby included 10 informants: four players (all males), four parents (three males, one female), the head coach of Bryne 99 (male), and one player development staff (male). All informants had been involved in the team for approximately 10 years or longer and thus had to retroactively recall relevant information.

\section{Data Collection}

The present study was approved by the ethics committee of the relevant university and the Norwegian Social Science Data Services. Informed consent from all informants was obtained prior to data collection. A semi-structured interview guide ${ }^{2}$ (Kvale, 1994) grounded in existing literature (Côté et al., 2016) was developed to help direct the interview toward topics of interest. The interview guide had three main parts, inspired by the dynamic elements of the PAF (activities, physical settings, and social dynamics). Sample questions included "Please describe how a typical organized practice session with the team was like for you" and "Please describe the social relationships within the team." In addition, the interviews addressed informants' background, as well as their general perception of the team over time. The general interview guide was adjusted for the distinct roles held by the individual interviewed (i.e., one for players, one for parents, one for the coach, and one for the club representative). 
In addition, a timeline methodology was applied for the four players in the first part of the interview (see Adriansen, 2012; Allan et al., 2019). In this phase, the interviewer and athletes used a timeline to mark the informant's soccer involvement, including milestones, transitions, and other important information throughout their career (e.g., important persons). This timeline was brought forward to the semi-structured interview to facilitate the informant's recall of their sport involvement throughout development, as recommended by Adriansen (2012). The last source of data for the present study was training diaries and records produced by the coach throughout the team's development. These documents contained the amount and content of the team's organized practice (e.g., sessions per week, duration, and focus area) throughout the distinct phases of development. These documents also recorded the start of participation in various forms of competitions (e.g., local league, regional tournaments, and national tournaments).

A pilot study of a Norwegian Premier League player was conducted to test the specific interview guide in a relevant setting. Based on the pilot, minor revisions were made to the interview guide. Prior to data collection, an appointment was made with the date and time for the 10 interviews. Eight interviews were conducted in person in a meeting room in Bryne, while the two remaining interviews were conducted online (i.e., via Skype and Messenger). The audio was recorded using a digital voice recorder, and each interview lasted between 19 and $61 \mathrm{~min}$ ( mean = $44 \mathrm{~min})$.

\section{Data Analysis}

The interviews were transcribed, and a thematic analysis was applied to identify patterns of meaningful units (Braun \& Clarke, 2006). The thematic analysis provides a theoretically flexible approach to analyzing qualitative data and has previously been applied in sport research on successful cases (Vierimaa et al., 2017). The first part of this analysis was inductive and included the review of the transcribed manuscripts and the coding of the texts into meaningful units. These units were organized into themes and sub-themes in the second part of the analysis. For example, "soccer-specific skills and knowledge" and "interest in the individual athlete" were examples of sub-themes that emerged under the broader theme of "the coach." Finally, the authors used a combined inductive and deductive approach, where the PAF (Côté et al., 2014) was used to organize the categories that corresponded with the dynamic elements of activities, physical settings, and social dynamics. No data were forced into the PAF categories; on the contrary, the content that did not fit into the dynamic elements of PAF were all related to some consequences of players' engagement with this team and were regrouped under a theme labeled "outcomes" (e.g., immediate and short-term outcomes).

\section{Results}

The thematic analysis resulted in the themes "outcomes," "activities," "social dynamics," and "physical settings." The findings from each theme are elaborated in the section below, and quotations (translated from Norwegian) from the informants are presented to illustrate and clarify the themes.

\section{Outcomes}

Immediate and Short-Term Outcomes. Both recreational and now professional players reported that playing soccer is an activity that provides immediate gratification and enjoyment: "I play soccer because it is fun" (Elite player 2) and "I love the sport ... . All of my friends love soccer" (Recreational player 1). Players described how their participation in the team fostered the development of soccer-specific skills. They added that values and norms within the team were transferred to other aspects of life; "We also pushed each other to perform at school" (Recreational player 2). The respondents further highlighted that the players on the team became close friends across skill levels and that it was important to show prosocial behaviors both on and off the soccer field.

Long-Term Outcomes. The coach described that the team was distinct from other teams on several parameters. Most prominently, the coach stated that "six out of 40 players have played for the Norwegian youth national team, and 10 of them have played for the regional team." Also, as previously described, six players obtained a professional senior contract (as of August 2020), including one player in the Norwegian Premier League and two international-level players with UEFA Champions League experience. Furthermore, data revealed that the team was highly successful in getting players to stay involved in the sport. Specifically, 35 of the 40 players who started on the team (at approximately age 6) participated in organized soccer throughout the team's existence. After that, most of the group continued playing soccer (i.e., continued in Bryne or were recruited to other clubs) throughout high school and until approximately age 19. Through the interviews, the players described that other teams in the region regularly experienced dropout, particularly from approximately age 13, while Bryne 99 remained a stable group. Indeed, all players recognized the uniqueness of the Bryne team, where team members were enjoying training and competitions during both childhood and adulthood and, thus, found no reasons to quit.

Although there was limited objective data to support team members' personal development, all players and parents described that involvement in the team had positively contributed to various aspects of the players' lives. Specifically, within the soccer context, the team stood out for their positive behavior, and recreational player 2 stated:

Younger and elder players started earlier with alcohol and that kind of behaviour, while we were more serious with school and everything .... We cleaned the wardrobe after we used it, and when we played matches, we always thanked the opponents after the match.

The players, parents, coach, and club representative highlighted that respect and inclusion were values that were important in the soccer context and in the players' personal lives. Elite player 2 described that "I have become a much better person from being a part of this team." Furthermore, the interviews revealed that the players developed positive social interactions with teammates, coaches, and others and that the players still are friends that have contact on a regular basis.

\section{Activities}

Organized Practice. While the informants described that they were involved in additional sports throughout their development (e.g., gymnastics, handball, and athletics), the present section will focus on soccer-related activities. Examination of training diaries revealed that until players reached the age of 10 , the team had one to two organized practice sessions of $60 \mathrm{~min}$ each week (except holidays). During these sessions, the focus was on individual skill development and enjoyment. The coach also highlighted that an important area of focus during the early years was to present drills 
and activities that the players could also perform in a nonorganized setting. The amount of practice increased from two to three sessions weekly from the age of 11, until the team was divided into two groups at age 13 . From ages 13 to 19 years, one group engaged in two practice sessions of $90 \mathrm{~min}$ weekly, and the other group engaged in four to five practice sessions of $90 \mathrm{~min}$ weekly. Through interviews and analysis of training diaries, it was indicated that relational and tactical skills became increasingly more prominent from approximately 11 years of age. From approximately 15 years of age, positional skills (e.g., finishing skills for strikers) were more emphasized.

Elite player 1 described that "We did not think about it at the time, but the coach had different focus areas throughout the years. That was different compared to other teams." Particularly, it was described that organized practice in early years was characterized by playful activities, competitions, and individual skill development. "We had a lot of competitions during practice. A lot of skill development, and a lot of competition" (Elite player 1). From early youth years, there was an increased focus on practice with the deliberate intention of improving performance. Nevertheless, the interviews made it clear that the players perceived organized soccer as fun throughout all age categories: "I have always had fun at the practice sessions" (Recreational player 1).

Matches and Tournaments. Throughout ages 6-12, the team played soccer matches against other local clubs but did not participate in tournaments. From age 13, the team started playing tournaments in addition to their regional league participation. Matches were typically played once a week from mid-April to mid-October (except July). Training histories and interviews showed that the team participated in approximately three tournaments per year, distributed between both elite and recreational tournaments.

Peer-Led Activities. The players reported that most of their soccer involvement throughout childhood was peer-led soccer play activities. The players described that this activity often was performed in local soccer fields-most often in the local soccer dome - and that it became a routine to play soccer on the weekends. The players described that they developed a game they called "World Cup," where they divided the participants into equal teams and played matches like the real World Cup. The players described this as a joyful yet competitive activity. The players also described that they played soccer whenever they could, such as between classes during school. "At elementary school, we played soccer each break, even if it was only a 10-min break" (Recreational player 2 ). The interviews revealed that peer-led soccer activities were conducted by players across all skill levels. Further, it was described that the amount of soccer play was most prominent throughout childhood and declined as players got older, and the amount of organized practice increased.

Activities in Relation to Outcomes. In summary, interviews and training diaries revealed that the activity involvement of the group in early years (approximately 6-10 years) were characterized by relatively small amounts of organized practice sessions, characterized by enjoyment, play activities, and individual skill development. Furthermore, many players engaged in substantial amounts of peerled soccer play, characterized by play, enjoyment, and competition. From approximately age 11, the activity involvement of the group was characterized by increased amounts of organized practice, characterized by individual skill development, competitions, relational skills and enjoyment, and reduced involvement in peer-led soccer activities.
All players described that participation in both peer-led and organized soccer gave them immediate gratification and enjoyment and that soccer was an important social arena. To achieve prominent performance levels, the respondents highlighted the importance of peer-led soccer activities and a combination of enjoyment and quality at organized practice. To explain individual differences in performance, the players who progressed to professional soccer highlighted that they had worked harder and engaged in more hours of practice compared with less skilled players. Furthermore, the players highlighted that quality practice, enjoyment, and optimal challenges for all players were important to keep players involved in sport over time.

\section{Social Relationships}

Culture and Role Models. The informants described the city of Bryne as "a soccer place" and noted that the senior teams have traditionally performed relatively well in the Norwegian setting. Furthermore, the team had several proximal role models, as both coaches and parents had played soccer professionally. "We had coaches that played at a high level and knew what it takes" (Recreational player 2). Players described that the culture and proximity to role models made it natural to participate in soccer, and further aim to progress to the highest level.

Team Aspects. All respondents described a group with strong and positive social connections, as indicated in sources described in the "Methods" section (i.e., coach presentations and articles in Norwegian newspapers). For instance, elite player 2 stated that "We were a large group of friends that played soccer together," and recreational player 2 stated that "You were friends with approximately 40 people. I had a lot of friends there." The respondents described that the players from a young age were friends across skill levels and would socialize at school, practice, and in their spare time. Respondents further described that the group developed a climate where they pushed each other to train and learn. This involved a climate for attending organized and peer-led soccer activities, and for making the most out of the practice sessions. "When we were at training it was to train - it was not just fooling around" (Elite player 1). "We have always pushed each other, without anything negative. Always positive and motivational. Then we have seen that people make it to a higher level, and that pushes others to get to an even higher level" (Recreational player 2).

Coach Aspects. The head coach was the parent of two players and served as head coach from when the players started playing organized soccer (at approximately age 6). In addition, other parents were involved in the team throughout the years. Both parents and players described that the head coach had detailed knowledge of the game, and the parents highlighted that he and the other coaches sought input to further develop their coaching. This is underpinned by the fact that the head coach had a UEFA A license, and two other parents that were involved as coaches had a UEFA B license (the third highest coaching license). The rest of this section will focus on the head coach.

All players and parents described that the head coach developed close relationships with the players and that it was highly important for him to see and talk to all players each session: "He was crazy about that; 'Who did I see today? Now I have to talk to this person next training.' He went through like that, so he was sure to interact with all players every week" (Elite parent 1). All respondents further described that the skilled and less skilled 
players were equally important for the coach. The coach described that "They (the players) have understood that we don't rate human worth based on whether you are good or bad at kicking a ball." Similarly, elite player 1 described that "If it was the best or the worst player-he treated them equally. We had some players that barely could hit a ball. But it did not matter." The coach elaborated that the connection with his players is a central part of his coaching philosophy.

To be recognized as a person is a fundamental thing. It builds confidence. In contrast; the most common form of bullying in a workplace or elsewhere is ignoring people, or not see them. That gives people an incredibly bad feeling.

The players and parents further described that the head coach challenged the players as players and persons. For instance, elite player 2 described:

He asked questions and did not always give us the answer. I remember we played a match in the regional series, and there was a striker we couldn't handle. The coach told us that he knew how we could handle the striker, but he wanted us to figure it out ourselves. He challenged us all the time.

Furthermore, the respondents highlighted that the head coach was a good role model, that he treated all players, referees, and opponents with respect. For instance, it was described that he did not yell at players if they made a mistake or behaved in discrepancy with desired values, but rather invited players to talk and discuss the situation. The coach also encouraged the players to make positive choices in life, such as prioritizing school: "The coach has always expressed that school comes first, no matter what" (Recreational player 1). See Table 1 for subcategories and examples of the various coach aspects.

Social Relationships in Relation to Outcomes. The interviews indicated that specific characteristics of the social relationships of the group contributed to multiple adaptive outcomes. For instance, close relationships with teammates and the coach were highlighted as beneficial for enjoyment during practice sessions and highlighted as important for both continued participation and the development of soccer skills. Yet, factors that emerged as important in relation to the development of prominent levels of performance were (a) proximity to role models; (b) competitiveness within a socially safe environment; and (c) having a highly competent coach who provided support, challenges, and inspiration. The camaraderie among all members and a coach who established close relationships with all players was described as important to prevent drop-out. In addition, the coach's focus on positive values influenced the individuals in their everyday lives, for instance, to prioritize school and to be respectful toward others.

\section{Physical Settings and Competitive Structure}

Facilities. A soccer dome was placed centrally in Bryne when the players were 5-6 years old. The dome had artificial turf and was unlocked and available for the players. Elite player 1 highlighted that the facilities became more accessible for peer-led activities after changing from natural to artificial turf, "It was natural grass there earlier, and then we weren't allowed to be there. But when they changed to artificial turf it became an area where many went to practice." In addition, there were other available soccer fields around the city, including a soccer field at school. Elite player 2 stated, "We have been very fortunate to have the soccer dome so we could train year-around." "The soccer dome was always open. If the soccer dome was occupied, there was an available soccer field just outside" (Elite player 1). The players and parents further described that accessibility to facilities allowed the players to participate in regular peer-led activities; "The cohort we talk about here was raised in that dome" (Elite parent 1).

Organization of the Team. From the beginning, a vision for the team was developed by the coaches; "As many as possible, for as long as possible, and as good as possible." However, the interviews indicated that the coaches placed less emphasis on the performance aspect of the vision. Specifically, the players reported that "To have as many as possible for as long as possible. I think that has been their (the coaches) main goal" (Elite player 2). Furthermore, the club representative stated that "The overriding aim has always been that all players should be proper citizens .... Whether they become [professional] soccer players or not is less important."

The team was one unit until the players were approximately 13 years of age, where they divided into two groups/teams due to various motives and ambitions in the group. It was described that the only difference between the two groups was the amount of organized practice conducted, where one team (hereafter "elite team" for clarity purposes) had four to five weekly practice sessions, and the other team (hereafter "recreational team") had two weekly practice sessions. The teams shared training hours for two sessions weekly, which allowed recreational and elite players

\section{Table 1 Overview With Description and Examples of Subcategories on Coach Dimensions}

\begin{tabular}{|c|c|c|}
\hline Subcategory & Description & Example \\
\hline Professional knowledge & $\begin{array}{l}\text { Knowledge of the game (e.g., drills } \\
\text { and tactics). }\end{array}$ & $\begin{array}{l}\text { "We were lucky to have (name of the coach) because he had a lot of soccer } \\
\text { competence." (Elite player 1) }\end{array}$ \\
\hline Eager to learn & $\begin{array}{l}\text { Seeking ways to improve his } \\
\text { coaching }\end{array}$ & $\begin{array}{l}\text { "They have been travelling around in the world. Attended coach seminars in } \\
\text { England, Germany, Netherlands. Got updated." (Elite parent 1) }\end{array}$ \\
\hline Development oriented & $\begin{array}{l}\text { Focused on the learning process rather } \\
\text { than performance }\end{array}$ & $\begin{array}{l}\text { "He asked questions and did not always give us the answer. I remember we played } \\
\text { a match in the regional series, and there was a striker we couldn't handle. The } \\
\text { coach told us that he knew how we could handle the striker, but he wanted us to } \\
\text { figure it out ourselves. He challenged us all the time." (Recreational player 2) }\end{array}$ \\
\hline $\begin{array}{l}\text { Close coach-athlete } \\
\text { relationships }\end{array}$ & $\begin{array}{l}\text { Established positive relationships } \\
\text { with all players }\end{array}$ & $\begin{array}{l}\text { "He was crazy about that; "Who did I see today? Now I have to talk to this person } \\
\text { next training." He went through like that, so he was sure to interact with all players } \\
\text { every week." (Elite parent } 1 \text { ) }\end{array}$ \\
\hline Role model & $\begin{array}{l}\text { Positive influence through words and } \\
\text { actions }\end{array}$ & "He was serious in everything he did." (Elite player 1) \\
\hline
\end{tabular}


to still interact within the soccer setting (e.g., walk/bicycle to practice and sharing team clothing). The interviews revealed that the distribution of players between the teams was not based on player ability but based on how much organized soccer the players wanted to engage in. The coach described that, beyond the amount of practice, the two groups were treated equally:

Even if it was the recreational team, the sessions were properly organized. Even if they only trained 1-2 times a week, it was always good structure on the practice sessions and planned preparation for matches. When we met other reserve [recreational] teams, the other teams made a big fuss out of being only the reserves. Just nonsense. But we did things seriously. It was allowed to smile, but we took them seriously.

Competitions. When playing matches in the early years, the larger group of 40 players was divided into smaller teams, with skilled and less skilled players playing together. The respondents reported that the coaches distributed the playing time equally and did not emphasize the importance of winning. It was described that equal playing time continued when they became youth players (i.e., from age 13) and that this contrasted with the other clubs that prioritized their best players from a younger age. "It was always that everybody should play equally. That everybody should have fun. Winning matches at young age was not important-it was more about development" (Recreational player 2). It was described that both parents and players generally acknowledged the value of equal playing time. Recreational player 2 further elaborated:

If their [the coaches] goal was to win the division when we were 13,14 or 15 [years old], we could have done it. But they rather preferred to make it more equal and develop the players. Rather than putting together a team that could win $6-0$, they put the best players with the players that was not that skillful.

Physical Settings in Relation to Outcomes. All respondents highlighted that the group had almost unlimited access to facilities, which enabled players to engage in substantial amounts of peer-led soccer activities that help them develop their soccer skills. In addition, the soccer dome was highlighted as central in the players' childhoods, as it became an important social arena where the children developed strong social bonds. In relation to the organization of the team, the respondents highlighted that dividing the group into teams of equal strength (rather than putting the best players together), and equal distribution of playing time was instrumental in establishing positive social relations across skill levels. Further, equality during competitions was argued to prevent less skilled players from being demotivated and dropping out and also positive for the development of skilled players (e.g., in terms of taking more responsibility). When dividing into two teams and training groups, the players highlighted that sharing training hours was important for social well-being and continued participation. "Although we were on two different teams, we were still with our friends" (Recreational player 2). "Other teams were divided into a first and second team from age 13 which operated separately. Then people dropped out" (Elite player 1).

\section{Discussion}

The purpose of the present study was to conduct a case study of an age-restricted soccer team that was successful in developing multiple long-term outcomes for individual participants (i.e., participation, performance, and positive development), and to investigate perceptions and experiences through the underlying mechanism of the physical settings, social dynamics, and sport activities that may have led to these adaptive outcomes. A soccer team from Bryne in Norway was selected due to the alignment with the attainment of the 3 P's (performance, participation, and personal development) within the PAF (Côté et al., 2014). While researchers have pinpointed the potential challenges in obtaining multiple adaptive outcomes simultaneously (Côté \& Abernethy, 2012), and previous studies have tended to focus on groups that have been successful in achieving one outcome (e.g., Balish \& Côté, 2014; Henriksen et al., 2014), the present study contributes to the existing literature by yielding insight into how the various dynamic elements of sport may be structured and implemented to promote individuals' attainment of performance, participation, and personal development from childhood to adulthood.

Regarding engagement in activities, the respondents in the present study described a developmental pathway characterized by substantial amounts of enjoyable peer-led soccer activities, which aligns with the early sampling pathway in the DMSP model (Côté et al., 2007). The respondents further argued that enjoyable sport experiences were beneficial for their continued motivation to practice and participate and contributed to the development of positive relationships with peers. Accordingly, the DMSP contends that early engagement in peer-led play activities promotes the longterm outcomes of performance, participation, and personal development, while early investment in large amounts of deliberate forms of practice may lead to high levels of performance but reduces the likelihood of long-term participation and enjoyment (Côté et al., 2007). Empirical evidence has generally supported the current findings and the theoretical predictions of the DMSP-model by associating early engagement in playful activities to more positive developmental outcomes than early engagement in more deliberate forms of practice (see e.g., Côté \& Vierimaa, 2014; Waldron et al., 2020). However, in line with other studies in the soccer context (e.g., Ford et al., 2009), the activities described by the Bryne players were mainly restricted to the soccer context, indicating that positive developmental outcomes may occur from diversification within a sport (e.g., small-sided games, drills, and adapted games, i.e., soccer tennis). Further, although the amount of organized practice was relatively low (one to two sessions each week from ages 6 to 10), the respondents highlighted the importance of having properly organized practice sessions with quality coaching also during the early years. The quality and microstructure of early practice engagement is rarely emphasized in research involving practice histories of successful athletes (Erikstad et al., 2018; Haugaasen et al., 2014). The coaches of Bryne generally structured practice sessions with much playing form activities and less traditional instruction, which previously has been argued to be beneficial for developing an understanding of the game and sportspecific decision-making skills (see Cushion et al., 2012). The sport experiences described by the informants may also lay a foundation for a lifelong healthy lifestyle, as research generally indicates that sport participation in childhood is associated with higher levels of physical activity in adulthood (Tammelin et al., 2003): specifically, perceptions of fun and enjoyment in sport can promote an active and healthy lifestyle (Visek et al., 2014).

Further, the respondents in the study described Bryne as a "soccer place" with residents sharing pride in the local soccer club. Similarly, Balish and Côté (2014) found that "community pride" was a key characteristic in their case study of a small community that successfully developed elite athletes. The respondents in the present study also highlighted the beneficial role of proximal 
role models, which also is similar to characteristics highlighted in previous case studies that have mainly focused on successful attainment of the isolated outcome of performance (Balish \& Côté, 2014; Henriksen et al., 2010a; Henriksen et al., 2011). In the present case, these role models were parents and coaches with international experience in professional soccer. In addition to the beneficial aspect of these role models in promoting and supporting the athletes' performance, the present findings also highlight the potential role for these role models in promoting personal development among players, for instance, by encouraging the players to prioritize school and pro-social values.

The respondents described that all members of the team were friends and that the team developed a competitive yet supportive climate that promoted both the amount and quality of practice. The importance of peers and teammates is generally acknowledged within the sport literature (Martin et al., 2014) as well as in previous case studies (e.g., Henriksen et al., 2010b; Vierimaa et al., 2017). From a group dynamics perspective, such a description of the team can relate to high levels of both social and task cohesion (e.g., see Carron \& Eys, 2012). In line with the respondent's descriptions of the beneficial role of the group climate in terms of both skill development, continued participation, and establishing positive interactions with peers, previous studies have found the task and/or social cohesion to be positively associated with both performances, participation, and personal development indicators (Bruner et al., 2014; Eys et al., 2009).

Further, Côté and Gilbert (2009) have proposed that coaches influence athletes' four C's, and thus three P's, over time, through their professional, interpersonal, and intrapersonal knowledge and behaviors. The head coach of Bryne was described to have detailed knowledge of the game (i.e., professional knowledge), and he organized quality practice sessions and helped players to learn. Although the interview did not focus on how the coach developed his coaching philosophy, it may be that the coach's teaching background has shaped his holistic approach to coaching. Further, the respondents described that the head coach displayed multiple positive leadership qualities (e.g., role model, development-oriented, and positive coach-athlete relationships) that closely align with the four I's of transformational leadership (see Bass \& Riggio, 2006; Turnnidge \& Côté, 2018). Indeed, a growing body of literature highlights the potential beneficial role of transformational leadership for athletes adaptive outcomes, such as motivation, commitment, perceived competence, and the development of personal and social skills (see Arthur et al., 2017; Turnnidge \& Côté, 2016). The coach's focus on pro-social behaviors and an inclusive learning environment emerged as important factors for the development of the previously described team climate. Such findings may not be surprising, as past research has indicated a positive relationship between transformational leadership and cohesion in sport (Smith et al., 2013) and between caring climates and task-involving climates (Hall et al., 2017). It was described that the parents generally had good faith in the coach, which is of relevance as Gledhill and Harwood (2015) highlighted in their case study the importance of the various social agents (e.g., parents, coaches, and teachers) coherently interacting for avoiding negative sport experiences.

Finally, regarding physical settings and competitive structure, the team was established in a smaller community and had unlimited access to high-quality facilities through the local soccer dome. The existing literature indicates that such settings are beneficial for the development of the three P's over time, as athletes from smaller cities are more likely to become elite athletes (Côté et al., 2006), experience personal development (Fraser-Thomas et al., 2010), and stay engaged in sport over time (Imtiaz et al., 2014) compared with athletes from bigger cities. While recreational sport participation generally focuses on positive social interactions and enjoyment, in contrast to development/performance contexts that primarily focuses on skill development (Trudel \& Gilbert, 2006), the present case was organized to promote both recreational and competitive participation. In line with previous case studies of successful environments (Balish \& Côté, 2014; Vierimaa et al., 2017), the variability of abilities was argued to allow the more skilled player to take more responsibility and develop leadership skills through peerfacilitated learning. Further, equality during competitions (i.e., mixed skill teams and equal distribution of playing time) was argued to prevent less skilled players from being demotivated and dropping out. The results of the present study further indicated that team stability contributed to the athletes' positive developmental experiences, and that this was promoted through shared training hours and no de-selection. Although challenges and setbacks (e.g., de-selection) may be beneficial for an athlete's development (Collins et al., 2016), stable social relationships through an athlete's development are generally considered beneficial (Balish \& Côté, 2014).

Limitations of the study must be considered when interpreting the findings. First, the study did not investigate other cases, and it is thus hard to firmly establish the uniqueness of the team. While the team undoubtedly was successful in developing good athletes and preventing drop-out, the athletes' attainment of personal development through their involvement is more difficult to objectively establish. Further, the respondents had to recall over 10 years back when describing the dynamic elements. Although a timeline methodology was applied to facilitate respondents' recall (see Adriansen, 2012), the study may be subject to recall biases (Côté et al., 2005). Although minor issues were mentioned when asking about negative aspects (e.g., single events regarding playing time), the informants generally drew an almost ideal picture of the team. However, based on the positive outcomes attained, it may be that informants have overstated the positive characteristics described in the results and made causal interpretations that do not exist.

In addition, an ethical consideration was completed on the decision to name the relevant soccer team. For instance, naming the team may increase publicity for the players and coaches on the team. However, it was considered impossible to describe the uniqueness of the case without presenting information that could identify the team. In addition, the case has already been identified and profiled in the media for its positive outcomes. Thus, it was decided that naming the team was both necessary and ethically justifiable.

\section{Practical Recommendations}

From a practical standpoint, the present study yields insight into how the various dynamic elements of sport participation may be structured and implemented to promote individuals' attainment of the P's. From a system perspective, the case has highlighted that the three P's are not mutually exclusive. Sport organizations and clubs should, therefore, be careful to not build systems that reduce individuals' opportunities for long-term engagement and/or personal development (e.g., promoting early specialization, early focus on results, and selection of athletes). Further, a central finding of the present case was the instrumental role of the coach and his transformational leadership behaviors in facilitating the positive outcomes attained. Notably, coaches' leadership behaviors have recently been contextualized within the sport setting through 
systematic observations (Turnnidge \& Côté, 2019). Other coaches should thus aim to implement transformational leadership behaviors in their daily practice (e.g., discussing and modeling prosocial values or behaviors, expressing confidence in athletes' capabilities, emphasizing the learning process, and showing interest in athletes' needs), as the present study aligns with previous studies in highlighting the positive role of transformational leadership for various performance-, participation-, and personal development-related outcomes in sports (Arthur et al., 2017; Stenling \& Tafvelin, 2014).

\section{Notes}

1. The regional team consists of approximately 25 of the most promising players from each age cohort between ages 13 and 16 years in the Rogaland region, which has approximately 450,000 inhabitants.

2. Interview guide available upon request.

\section{References}

Adriansen, H. (2012). Timeline interviews: A tool for conducting life history research. Qualitative Studies, 3(1), 40-55. https://doi.org/10.7146/qs. v3i1.6272

Allan, V., Evans, M.B., Latimer-Cheung, A.E., \& Côté, J. (2019). From the athletes' perspective: A social-relational understanding of how coaches shape the disability sport experience. Journal of Applied Sport Psychology, 32(6), 546-564. https://doi.org/10.1080/10413200.2019. 1587551

Allen-Collinson, J. (2009). Sporting embodiment: Sports studies and the (continuing) promise of phenomenology. Qualitative Research in Sport and Exercise, 1(3), 279-296. https://doi.org/10.1080/193984 40903192340

Arthur, C.A., Bastardoz, N., \& Eklund, R. (2017). Transformational leadership in sport: Current status and future directions. Current Opinion in Psychology, 16, 78-83. PubMed ID: 28813361 https://doi. org/10.1016/j.copsyc.2017.04.001

Baker, J., \& Young, B. (2014). 20 years later: Deliberate practice and the development of expertise in sport. International Review of Sport and Exercise Psychology, 7(1), 135-157. https://doi.org/10.1080/ 1750984X.2014.896024

Balish, S., \& Côté, J. (2014). The influence of community on athletic development: An integrated case study. Qualitative Research in Sport, Exercise and Health, 6(1), 98-120. https://doi.org/10.1080/ 2159676X.2013.766815

Bass, B.M., \& Riggio, R.E. (2006). Transformational leadership. Psychology Press.

Braun, V., \& Clarke, V. (2006). Using thematic analysis in psychology. Qualitative Research in Psychology, 3(2), 77-101.

Bruner, M.W., Eys, M.A., Wilson, K.S., \& Côté, J. (2014). Group cohesion and positive youth development in team sport athletes. Sport, Exercise, and Performance Psychology, 3(4), 219-227. https:// doi.org/10.1037/spy0000017

Carron, A.V., \& Eys, M. (2012). Group dynamics in sport (4th ed.). Fitness Information Technology.

Collins, D.J., Macnamara, A., \& McCarthy, N. (2016). Putting the bumps in the rocky road: Optimizing the pathway to excellence. Frontiers in Psychology, 7, 1482. PubMed ID: 27733841

Côté, J. (1999). The influence of the family in the development of talent in sport. Sport Psychologist, 13(4), 395-417. https://doi.org/10.1123/ tsp.13.4.395
Côté, J., \& Abernethy, B. (2012). A developmental approach to sport expertise. In Murphy, S. (Ed.), The Oxford handbook of sport and performance psychology (pp. 435-447). Oxford University Press.

Côté, J., \& Gilbert, W. (2009). An integrative definition of coaching effectiveness and expertise. International Journal of Sports Science \& Coaching, 4(3), 307-323. https://doi.org/10.1260/17479540 9789623892

Côté, J., \& Vierimaa, M. (2014). The developmental model of sport participation: 15 years after its first conceptualization. Science \& Sports, 29, S63-S69.

Côté, J., Baker, J., \& Abernethy, B. (2007). Practice and play in the development of sport expertise. In R. Eklund, \& G. Tenenbaum (Eds), Handbook of Sport Psychology (pp. 184-202). John Wiley \& Sons, Inc.

Côté, J., Bruner, M., Erickson, K., Strachan, L., \& Fraser-Thomas, J. (2010). Athlete development and coaching. In J. Lyle \& C. Cushion (Eds), Sports coaching: Professionalisation and practice (pp. 63-84). Churchill Livingstone.

Côté, J., Ericsson, K.A., \& Law, M. (2005). Tracing the development of athletes using retrospective interview methods: A proposed interview and validation procedure for reported information. Journal of Applied Sport Psychology, 17,(1) 1-19. https://doi.org/10.1080/104132005 90907531

Côté, J., Macdonald, D.J., Baker, J., \& Abernethy, B. (2006). When "where" is more important than "when": Birthplace and birthdate effects on the achievement of sporting expertise. Journal of Sports Sciences, 24(10), 1065-1073. PubMed ID: 17115521 https://doi.org/ $10.1080 / 02640410500432490$

Côté, J., Turnnidge, J., \& Evans, M.B. (2014). The dynamic process of development through sport. Kinesiologia Slovenica, 20(3), 14-26. ISSN: 13182269

Côté, J., Turnnidge, J., \& Vierimaa, M. (2016). A personal assets approach to youth sport. In K. Green \& A. Smith (Eds), Routledge handbook of youth sport (pp. 243-255). Routledge.

Côté, J., Turnnidge, J., Murata, A., McGuire, C., \& Martin, L. (in press). Youth sport research: Describing the integrated dynamics elements of the Personal Assets Framework. International Journal of Sport Psychology.

Coutinho, P., Mesquita, I., \& Fonseca, A.M. (2016). Talent development in sport: A critical review of pathways to expert performance. International Journal of Sports Science \& Coaching, 11(2), 279-293. https://doi.org/10.1177/1747954116637499

Crane, J., \& Temple, V. (2015). A systematic review of dropout from organized sport among children and youth. European Physical Education Review, 21(1), 114-131. https://doi.org/10.1177/1356 336X14555294

Curtis, J.E., \& Birch, J.S. (1987). Size of community of origin and recruitment to professional and Olympic hockey in North America. Sociology of Sport Journal, 4(3), 229-244. https://doi.org/10.1123/ ssj.4.3.229

Cushion, C., Ford, P.R., \& Williams, A.M. (2012). Coach behaviours and practice structures in youth soccer: Implications for talent development. Journal of Sports Sciences, 30(15), 1631-1641. PubMed ID: $23016800 \mathrm{https} / / /$ doi.org/10.1080/02640414.2012.721930

DiSanti, J.S., \& Erickson, K. (2020). Challenging our understanding of youth sport specialization: An examination and critique of the literature through the lens of Bronfenbrenner's Person-ProcessContext-Time Model. International Review of Sport and Exercise Psychology, 1-23. https://doi.org/10.1080/1750984X.2020.1728779

Eime, R.M., Sawyer, N., Harvey, J.T., Casey, M.M., Westerbeek, H., \& Payne, W.R. (2015). Integrating public health and sport management: Sport participation trends 2001-2010. Sport Management Review, 18(2), 207-217. https://doi.org/10.1016/j.smr.2014.05.004 
Eime, R.M., Young, J.A., Harvey, J.T., Charity, M.J., \& Payne, W.R. (2013). A systematic review of the psychological and social benefits of participation in sport for children and adolescents: Informing development of a conceptual model of health through sport. International Journal of Behavioral Nutrition and Physical Activity, 10(1), 98. https://doi.org/10.1186/1479-5868-10-98

Erikstad, M.K., Høigaard, R., Johansen, B.T., Kandala, N.-B., \& Haugen, T. (2018). Childhood football play and practice in relation to selfregulation and national team selection; a study of Norwegian elite youth players. Journal of Sports Sciences, 36(20), 2304-2310. PubMed ID: 29521180 https://doi.org/10.1080/02640414.2018. 1449563

Etikan, I., Musa, S.A., \& Alkassim, R.S. (2016). Comparison of convenience sampling and purposive sampling. American Journal of Theoretical and Applied Statistics, 5(1), 1-4. https://doi.org/10. 11648/j.ajtas.20160501.11

Eys, M., Loughead, T., Bray, S.R., \& Carron, A.V. (2009). Perceptions of cohesion by youth sport participants. Sport Psychologist, 23(3), 330-345. https://doi.org/10.1123/tsp.23.3.330

Ford, P.R., \& Williams, A.M. (2017). Sport activity in childhood: Early specialization and diversification. In J. Baker, S. Cobley, J. Schorer, \& N. Wattie (Eds.), Routledge handbook of talent identification and development in sport (pp. 117-132). Routledge.

Ford, P.R., Coughlan, E.K., Hodges, N.J., \& Williams, A.M. (2015). Deliberate practice in sport. In J. Baker \& D. Farrow (Eds.), Routledge handbook of sport expertise (pp. 305-316). Routledge.

Ford, P.R., Ward, P., Hodges, N.J., \& Williams, M.A. (2009). The role of deliberate practice and play in career progression in sport: The early engagement hypothesis. High Ability Studies, 20(1), 65-75. https:// doi.org/10.1080/13598130902860721

Fraser-Thomas, J., Côté, J., \& Deakin, J. (2008). Understanding dropout and prolonged engagement in adolescent competitive sport. Psychology of Sport and Exercise, 9(5), 645-662. https://doi.org/10.1016/j. psychsport.2007.08.003

Fraser-Thomas, J., Côté, J., \& MacDonald, D.J. (2010). Community size in youth sport settings: Examining developmental assets and sport withdrawal. Revue phénEPS/PHEnex Journal, 2(2), 1-9.

Fredricks, J.A., \& Eccles, J.S. (2006). Is extracurricular participation associated with beneficial outcomes? Concurrent and longitudinal relations. Developmental Psychology, 42(4), 698-713. PubMed ID: 16802902 https://doi.org/10.1037/0012-1649.42.4.698

Gledhill, A., \& Harwood, C. (2015). A holistic perspective on career development in UK female soccer players: A negative case analysis. Psychology of Sport and Exercise, 21, 65-77. https://doi.org/10. 1016/j.psychsport.2015.04.003

Hall, M.S., Newland, A., Newton, M., Podlog, L., \& Baucom, B.R. (2017). Perceptions of the social psychological climate and sport commitment in adolescent athletes: A multilevel analysis. Journal of Applied Sport Psychology, 29(1), 75-87. https://doi.org/10.1080/ 10413200.2016.1174906

Haugaasen, M., \& Jordet, G. (2012). Developing football expertise: A football-specific research review. International Review of Sport and Exercise Psychology, 5(2), 177-201. https://doi.org/10.1080/ 1750984X.2012.677951

Haugaasen, M., Toering, T., \& Jordet, G. (2014). From childhood to senior professional football: A multi-level approach to elite youth football players' engagement in football-specific activities. Psychology of Sport and Exercise, 15(4), 336-344. https://doi.org/10.1016/j. psychsport.2014.02.007

Henriksen, K., Larsen, C.H., \& Christensen, M.K. (2014). Looking at success from its opposite pole: The case of a talent development golf environment in Denmark. International Journal of Sport and
Exercise Psychology, 12(2), 134-149. https://doi.org/10.1080/ 1612197X.2013.853473

Henriksen, K., Stambulova, N., \& Roessler, K.K. (2010a). Holistic approach to athletic talent development environments: A successful sailing milieu. Psychology of Sport and Exercise, 11(3), 212-222. https://doi.org/10.1016/j.psychsport.2009.10.005

Henriksen, K., Stambulova, N., \& Roessler, K.K. (2010b). Successful talent development in track and field: Considering the role of environment. Scandinavian Journal of Medicine and Science in Sports, 20 (Suppl.), 122-132. https://doi.org/10.1111/j.1600-0838.2010.01187.x

Henriksen, K., Stambulova, N.B., \& Roessler, K. (2011). Riding the wave of an expert: A successful talent development environment in Kayaking. Sport Psychologist, 25(3), 341-362. https://doi.org/10. $1123 /$ tsp.25.3.341

Holt, N. (2016). Positive youth development through sport. Routledge.

Hulteen, R.M., Smith, J.J., Morgan, P.J., Barnett, L.M., Hallal, P.C., Colyvas, K., \& Lubans, D.R. (2017). Global participation in sport and leisure-time physical activities: A systematic review and metaanalysis. Preventive Medicine, 95, 14-25. PubMed ID: 27939265 https://doi.org/10.1016/j.ypmed.2016.11.027

Imtiaz, F., Hancock, D.J., Vierimaa, M., \& Côté, J. (2014). Place of development and dropout in youth ice hockey. International Journal of Sport and Exercise Psychology, 12(3), 234-244. https://doi.org/10. 1080/1612197X.2014.880262

Kvale, S. (1994). Interviews: An introduction to qualitative research interviewing. Sage Publications, Inc.

Little, R.R. (1993). What's working for today's youth: The issues, the programs, and the learnings. Paper presented at the Institute for Children, Youth, and Families Fellows' Colloquium, Michigan State University.

Martin, Bruner, M., Eys, M., \& Spink, K. (2014). The social environment in sport: Selected topics. International Review of Sport and Exercise Psychology, 7(1), 87-105. https://doi.org/10.1080/ 1750984X.2014.885553

Memmert, D., Baker, J., \& Bertsch, C. (2010). Play and practice in the development of sport-specific creativity in team ball sports. High Ability Studies, 21(1), 3-18. https://doi.org/10.1080/13598139.2010. 488083

Myer, G.D., Jayanthi, N., Difiori, J.P., Faigenbaum, A.D., Kiefer, A.W., Logerstedt, D., \& Micheli, L.J. (2015). Sport specialization, part I: Does early sports specialization increase negative outcomes and reduce the opportunity for success in young athletes? Sports Health, 7(5), 437-442. PubMed ID: 26502420 https://doi.org/10.1177/ 1941738115598747

Norwegian Olympic and Paralympic Committee and Confederation of Sports. (2017). Nøkkeltall—Rapport 2016. https://www.idretts forbundet.no/contentassets/e7edfa47f77e457abf83827d39c3e1d8/ nokkeltallsrapport-2016.pdf

Patton, M.Q. (2002). Qualitative research and evaluation methods. Sage Publications.

Price, M.S., \& Weiss, M.R. (2013). Relationships among coach leadership, peer leadership, and adolescent athletes' psychosocial and team outcomes: A test of transformational leadership theory. Journal of Applied Sport Psychology, 25(2), 265-279. https://doi.org/10.1080/ 10413200.2012.725703

Rees, T., Hardy, L., Güllich, A., Abernethy, B., Côté, J., Woodman, T., ... Warr, C. (2016). The great British medalists project: A review of current knowledge on the development of the world's best sporting talent. Sports Medicine, 46(8), 1041-1058. PubMed ID: 26842017 https://doi.org/10.1007/s40279-016-0476-2

Schwartz-Shea, P., \& Yanow, D. (2013). Interpretive research design: Concepts and processes. Routledge. 
Skille, E.Å. (2011). Sport for all in Scandinavia: Sport policy and participation in Norway, Sweden and Denmark. International Journal of Sport Policy and Politics, 3(3), 327-339. https://doi.org/10.1080/ 19406940.2011.596153

Smith, M.J., Arthur, C.A., Hardy, J., Callow, N., \& Williams, D. (2013). Transformational leadership and task cohesion in sport: The mediating role of intrateam communication. Psychology of Sport and Exercise, 14(2), 249-257. https://doi.org/10.1016/j.psychsport.2012. 10.002

Stambulova, N. (1994). Developmental sports career investigations in Russia: A post-perestroika analysis. The Sport Psychologist, 8(3), 221-237. https://doi.org/10.1123/tsp.8.3.221

Stambulova, N., \& Alfermann, D. (2009). Putting culture into context: Cultural and cross-cultural perspectives in career development and transition research and practice. International Journal of Sport and Exercise Psychology, 7(3), 292-308. https://doi.org/10.1080/ 1612197X.2009.9671911

Stenling, A., \& Tafvelin, S. (2014). Transformational leadership and wellbeing in sports: The mediating role of need satisfaction. Journal of Applied Sport Psychology, 26(2), 182-196. https://doi.org/10.1080/ 10413200.2013.819392

Tammelin, T., Näyhä, S., Hills, A.P., \& Järvelin, M.-R. (2003). Adolescent participation in sports and adult physical activity. American Journal of Preventive Medicine, 24(1), 22-28. PubMed ID: 12554020 https://doi.org/10.1016/S0749-3797(02)00575-5

Thanh, N.C., \& Thanh, T. (2015). The interconnection between interpretivist paradigm and qualitative methods in education. American Journal of Educational Science, 1(2), 24-27

Tongco, M.D.C. (2007). Purposive sampling as a tool for informant selection. Ethnobotany Research and Applications, 5, 147-158 https://doi.org/10.17348/era.5.0.147-158

Trudel, P., \& Gilbert, W. (2006). Coaching and coach education. In D. Kirk, D. Macdonald, \& M. O'Sullivan (eds.) The handbook of physical education (pp. 516-539). Sage.

Tuastad, S. (2019). The Scandinavian sport model: Myths and realities. Norwegian football as a case study. Soccer \& Society, 20(2), 341-359. https://doi.org/10.1080/14660970.2017.1323738

Tucker, S., Turner, N., Barling, J., \& McEvoy, M. (2010). Transformational leadership and childrens' aggression in team settings: A short-term longitudinal study. The Leadership Quarterly, 21(3), 389-399. https://doi.org/10.1016/j.leaqua.2010.03.004

Turnnidge, J., \& Côté, J. (2016). Applying transformational leadership theory to coaching research in youth sport: A systematic literature review. International Journal of Sport and Exercise Psychology, 16, $1-16$.

Turnnidge, J., \& Côté, J. (2018). The theoretical underpinnings of transformational coaching in sport. In R. Thelwell \& M. Dicks (Eds.), Professional advances in sports coaching (pp. 22-43). Routledge.

Turnnidge, J., \& Côté, J. (2019). Observing coaches' leadership behaviours: The Development of the Coach Leadership Assessment System (CLAS). Measurement in Physical Education and Exercise Science, 23(3), 214-226. https://doi.org/10.1080/1091367X.2019. 1602835

Turnnidge, J., Hancock, D., \& Côté, J. (2014). The influence of birth date and place of development on youth sport participation. Scandinavian Journal of Medicine \& Science in Sports, 24(2), 461-468. https://doi. org/10.1111/sms.12002

Vella, S., Oades, L., \& Crowe, T. (2011). The role of the coach in facilitating positive youth development: Moving from theory to practice. Journal of Applied Sport Psychology, 23(1), 33-48. https://doi.org/10.1080/10413200.2010.511423

Vierimaa, M., Turnnidge, J., Bruner, M., \& Côté, J. (2017). Just for the fun of it: Coaches' perceptions of an exemplary community youth sport program. Physical Education and Sport Pedagogy, 22(6), 603-617. https://doi.org/10.1080/17408989.2017.1341473

Visek, A., Achrati, S., Manning, H., McDonnell, K., Harris, B., \& Dipietro, L. (2014). The fun integration theory: Toward sustaining children and adolescents sport participation. Journal of Physical Activity \& Health, 12(3), 424-433. PubMed ID: 24770788 https:// doi.org/10.1123/jpah.2013-0180

Waldron, S., DeFreese, J.D., Register-Mihalik, J., Pietrosimone, B., \& Barczak, N. (2020). The costs and benefits of early sport specialization: A critical review of literature. Quest, 72(1), 1-18. https://doi.org/ 10.1080/00336297.2019.1580205

Ward, Hodges, N.J., Starkes, J.L., \& Williams, M.A. (2007). The road to excellence: Deliberate practice and the development of expertise. High Ability Studies, 18(2), 119-153. https://doi.org/10.1080/13598 130701709715

Zell, E., \& Alicke, M.D. (2010). Comparisons over time: Temporal trajectories, social comparison, and self-evaluation. European Journal of Social Psychology, 40(3), 375-382.

Zimmermann-Sloutskis, D., Wanner, M., Zimmermann, E., \& Martin, B.W. (2010). Physical activity levels and determinants of change in young adults: A longitudinal panel study. International Journal of Behavioral Nutrition and Physical Activity, 7(1), 2. https://doi.org/10. 1186/1479-5868-7-2 